in the testing of the chromatic aberration of objectives, by those whose eye experiences cannot be a sufficiently accurate guide, to allow the image of a star, as found by the objective, to fall on the slit of a spectroscope, and to judge of the focus of each particular ray by the breadth of the spectrum at that ray. Wherever the light is brought to a focus the spectrum is of insensible breadth. When it is out of focus, a more or less sensible breadth, by moving the spectroscope in and out of the position of maximum and minimum foci, can be obtained.

I tried this plan, but found it very unsatisfactory, as it was very difficult to determine the exact place where the spectrum was narrowest, the curves being so very shallow.

After much thought I arrived at the following very simple and efficient plan, which I described in full, as it may be useful to some for other purposes. It should be remembered that the object is to get the focus of the objective for various parts of the spectrum.

If, therefore, we could obtain various objects when light was derived for such portions, and such portions only, of the spectrum as we required, our object would be accomplished.

I take a spectroscope with a fairly large dispersion equal to about 2 prisms of $60^{\circ}$ and with a pencil of light of about $2^{\circ}$ diameter. I remove the observing telescope, and substitute one of very long focus, so that the linear dimensions of the spectrum shall be as large as possible. I observe with this the solar spectrum, and note the position of such lines as I intend to work on. I then remove the eye-piece and insert in its place a tube carrying a small convex mirror. The apparatus is left till dark, and a small electric glass lamp attached outside the slit. The observing telescope is then placed at such a reading as I know will bring any certain line into the centre of the field, and on looking at the small mirror through a long slit which is purposely made on the top of the tube to allow it to be viewed from the front, you see a small bright star whose light is due to that particular line in the spectrum, and to no other part. The apparatus is placed at a sufficient distance in front of the photographic telescope, and these stars are the objects examined. In this way I can produce a small bright star of a colour corresponding to any of the lines in the spectrum, and the foci of these, as observed in the photographic telescope, can be measured with great exactitude.

There are, of course, small matters of detail which I have been tuable to touch upon in the present communication, many of which are very important for the effective working of these instruments, and which require special treatment. I have, however, confined myself to the principal and more important parts, but I trust that I have been able to show that we have at least made a substantial advance; and it remains for us to hope that when these instruments are placed in the hands of astronomers they may yield a rich harvest of work, and leave their mark on the history of astronomical science.

HOWARD GRUBB.

\section{ON THE PRINCIPLE AND METHODS OF ASSIGNING MARKS FOR BODILY EFFICIENCY.1}

THE question to be solved is of this kind. Suppose that one man can just distinguish a minute test object at the distance of 25 inches, another at that of 35 , and again another at 45 inches, how should we mark them? We should be very rash if we marked them in the proportion of 25,35 , and 45 , or even if, for some good reason, we had selected 25 as the lowest limit from which marks should begin to count, we should mark them as 0 , IO, and 20.

Read at the British Association, by Francis Galton, F.R.S. ; but slightly revised, in order to introduce the diagrams herewith printed. Followed by semarks on experiments made at Eton College, by. A. A. Somerville.
Two separate considerations are concerned in the just determination of a scale of marks-namely, absolute performance and relative rank, which are apt to be confused in unknown and varying proportions.

Absolute performance is such as is expressed by the 25 35 , and 45 inches just spoken of. It is perfectly correct in some cases to mark, or let us say to pay, for this, and this alone, upon the principle of piece-work-namely, that the pay ought to be proportionate to the work accomplished, or to the expected output in after life.

Relative rank is, however, on the whole, a more important consideration than the absolute amount of performance by which that rank is obtained. It has an importance of its own, because the conditions of life are those of continual competition, in which the man who is relatively strong will always achieve success, while the relatively weak will fail. The absolute difference between their powers matters little. The strongest even by a trifle will win the prize as completely as if he had been strongest by a large excess. Undertakings where many have failed, are accomplished at last by one who usually is very little superior to his predecessors, but it is to just that small increment of absolute superiority that his success is due. Therefore it is clear that relative rank has at least as strong a claim for recognition as absolute performance, if not a much stronger one. They have each to be taken into separate consideration, and each to be separately marked. The precise meaning intended to be conveyed by the phrase "relative rank" will be better understood further on.

Recurring to the example of keenness of eyesight, let the test object be words printed in diamond type, and the persons tested be Englishmen of the middle classes, between the ages of 23 and 26 , then the performance of readtng diamond type at 25 inches happens to be strictly mediocre. Fifty per cent. of the many persons who were tested performed better than this, and 50 per cent. performed worse. The 35 -inch performance was exceeded by only $2 \frac{1}{2}$ per cent. of the persons tested ; and as to the 45 -inch performance, it has not in my experience been reached at all. I have had altogether 12,000 persons tested in this way, of both sexes and of various ages, but not one of them has succeeded in reading diamond type at the distance of 45 inches. It is very rare to find one who can do so at 40 inches. Wherever superiority in eyesight is eminently desirable, it would be absurd to make the marks for the three supposed cases to run proportionately either to 25,35 , and 45 , or to 0 , IO, and 20 . The achievement of 45 inches would deserve much higher recognition. Relative rank and absolute performance should not be confused together.

I use the term relative rank in a large sense, with reference to all persons who have been, or are likely to become, candidates, and not to the small number of them who may happen to be present at a particular examination. Statistical tables concerning the class of persons in question have to be compiled from past examinations, and the rank of the individual has to be determined amidst these. I have often described how this is to be done ("Natural Inheritance," p. 38, Macmillan and Co., I 889), but the diagram (Fig. I) is, I think, the simplest of all forms for the use of an examiner. It tells at a glance the rank held by a man among his fellows in respect to any single and separate faculty. The class from which it is constructed might consist of any large number of persons subject only to the condition that the distance between the limits within which it extends shall be always divided into centesimal grades; that is to say, running from $0^{\circ}$ to $100^{\circ}$. The grades are printed along both the top and the bottom of the diagram, and refer alike to every line. As a specimen of the way to read it, let us take the line of keenness of eyesight among the males. Here we see that the performance of reading diamond type at the distance of 25 inches is appropriate 
to grade $50^{\circ}$; or, as already stated, 50 per cent. of all the persons tried did worse, and 50 per cent. did better. Therefore the performance in question is exactly mediocre. Again, 30 inches corresponds to grade $80^{\circ}$; in other words, 80 per cent. did worse and the remaining 20 per cent. did better. The method on which this diagram is constructed is of universal application. Calling the particular class of persons to which it refers, for brevity, by the letters I.H.E. (International Health Exhibition), then the rank of any individual among the I.H.E. males, aged $23-26$, in respect to any of the qualities therein named, can be most easily ascertained; also among the I.H.E. females of the same ages.

This method admits of being extended in more than

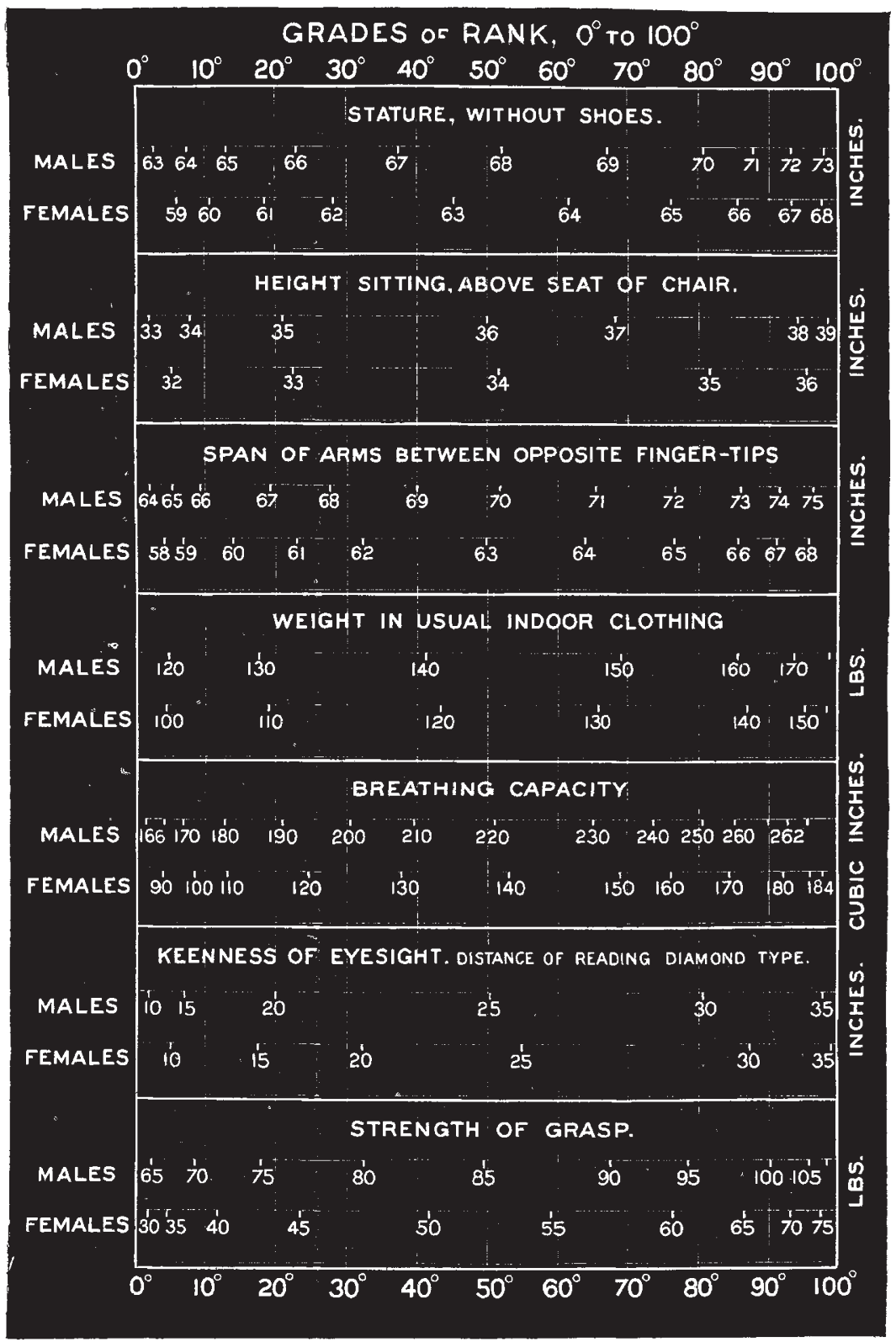

FIG, I.

one way. That for which there is most call is where the rank of the quality immediately in question, has to be considered in reference to some other quality. Thus it is of little use to know the breathing capacity of the man unless we also know his stature or his weight. Lungs capacious enough to enable a small man to labour violently without panting would be wholly insufficient for the ordinary purposes of a giant, just as an excellent little boiler for a small steam-engine would be ineffective with a large one. The diagram (see Fig. 2) appropriate to the case we are considering, could not be compressed into a single line, but requires many. Successive lines in that figure refer to the successive statures of 60 inches, $6 r$ inches," and so on up to 72 inches. A diagram of breath- 
ing capacities for each of these statures was constructed in pencil, on the principle of one of the lines in Fig. I ; then bold lines were drawn from above downward to connect all the pencilled entries of the same value, just as isobars, isotherms, and other contour lines are drawn (to which the general name of isograms might well be given). This completed the figure, which hardly needs further description, either how to make or to use it. The importance of taking stature into account now becomes very evident. A breathing capacity of 220 cubic inches in a man of 72 inches stature has the rank of only $6^{\circ}$, but in a man of 60 inches it has the rank of $94^{\circ}$. Fig. 3 shows in a similar way the grade of any given strength of grasp, when the weight of the person is taken into account.

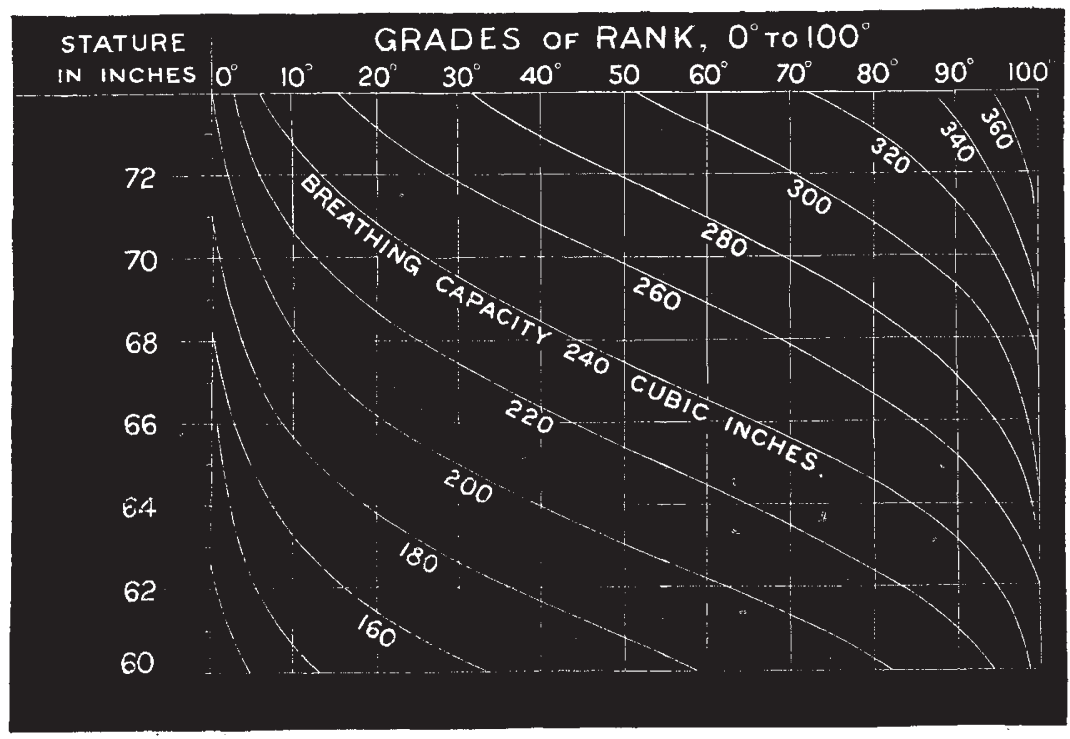

FIG. 2.

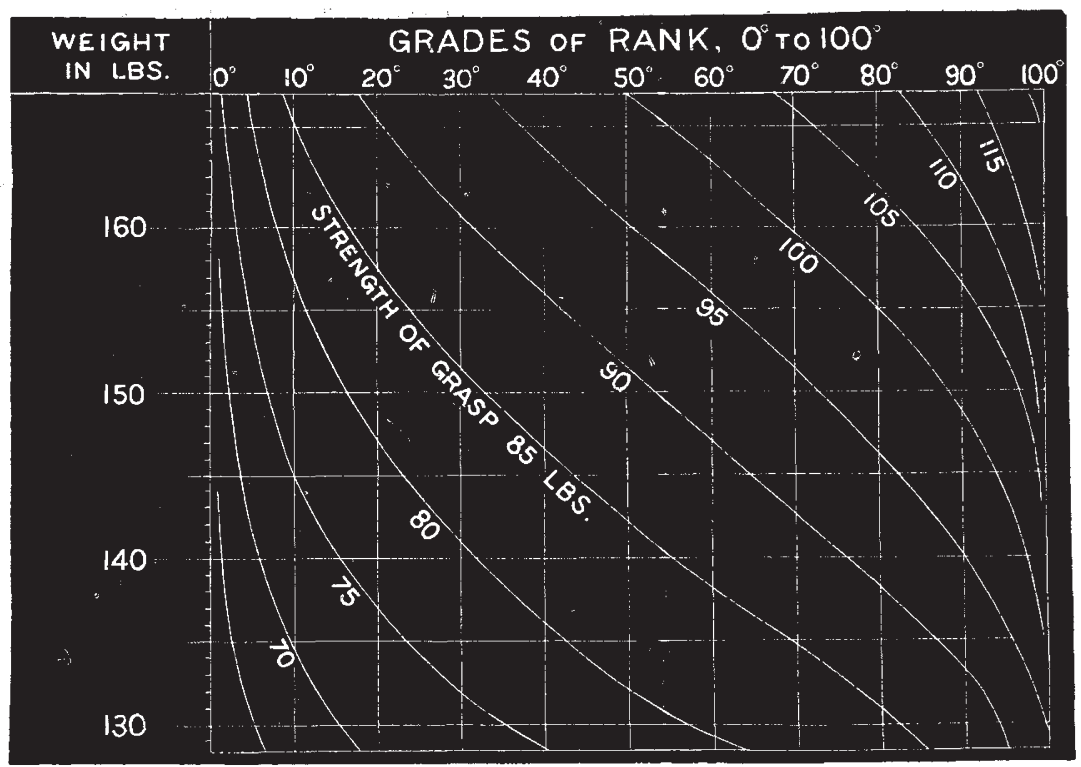

FIG. 3.

When the quality that has to be marked depends upon more than one other quality - as it may be desired to mark breathing capacity with reference both to weight and to stature - the simplest plan is to make a separate diagram for each inch or second inch of stature, which is quite near enough. I have, however, contrived to make a single page serve for the whole process by using a sliding strip of paper. I have submitted it for inspection, but do not care to describe it.

A strong reason for giving prominence to relative rank is that it affords the only feasible way of measuring many qualities; differences in absolute performance being inferred from rank, according to a principle now familiar to most anthropologists, by using the well-known table of 
the probability integral. A small table based on the latter, but of a totally different form, that I have lately more than once published (op. cit., p. 205, and NATURE, vol. xxxix. p. 297). is very convenient for this sort of work. The following is a brief extract from it :-

Grades of Rank from $0^{\circ}$ to $100^{\circ}$, together with the Deviations 1 from the Mean Valnes at those Grades.

\begin{tabular}{|c|c|c|c|c|c|}
\hline $\begin{array}{l}\text { Grades...... } \\
\text { Deviations }\end{array}$ & \begin{tabular}{c|c}
$0^{\circ}$ & $10^{\circ}$ \\
- infinity & $-\mathrm{I}^{\circ} 9$
\end{tabular} & $\begin{array}{c:c:c}20^{\circ} & 30^{\circ} & 40^{\circ} \\
-\mathbf{I}^{\circ} 3 & -0.8 & -0^{\circ} 4\end{array}$ & $\begin{array}{c:c}50^{\circ} & 60^{\circ} \\
0.0 & +0^{\circ} 4\end{array}$ & $\begin{array}{r}70^{\circ} 80^{\circ} \\
+0^{\circ} 8+13\end{array}$ & $\begin{array}{l}90^{\circ} \\
+r^{\circ} 9\end{array}$ \\
\hline $\begin{array}{l}\text { Grades...... } \\
\text { Deviations }\end{array}$ & $\begin{array}{cc}91^{\circ} & 92^{\circ} \\
+20 & +21\end{array}$ & $\begin{array}{r}93^{\circ}+94^{\circ} \\
+2^{\circ} 2+2^{\circ} 3\end{array}$ & $\begin{array}{r:r}96^{\circ} & 97^{\circ} \\
+26 & +2.8\end{array}$ & $\begin{array}{r}98^{\circ} \\
+3^{\circ} \\
+9^{\circ} \\
+3^{\circ} 5\end{array}$ & $\begin{aligned} & 100^{\circ} \\
+ & \text { infinity }\end{aligned}$ \\
\hline
\end{tabular}

Some of the consequences of marking separately the relative rank and the absolute performance are seen by the next table. Here the relative rank is in cach case supposed to count between the grades of $50^{\circ}$ and $100^{\circ}$. Then, if it alone is considered, a man who stands at the grade of $99^{\circ}$ in a class that ranges within the limits of $0^{\circ}$ and $100^{\circ}$, will be seen to get very nearly the full amount of ten marks, whereas if absolute performance is alone considered, he would get no more than seven marks. The full number of ten could be never actually reached, but only closcly approached at some such high grade as $99^{\circ} 99 \ldots$. The figures in this table would have run very differently if the marks for relative rank had begun after $90^{\circ}$ and not after $50^{\circ}$. Still more so, if the lower limit had been $99^{\circ}$, and more still if it had been $99^{\circ} 9$. It seems to me most reasonable, on the whole, that they should usually begin after $50^{\circ}$, as in the table :-

\begin{tabular}{|c|c|c|c|c|c|c|}
\hline \multicolumn{2}{|c|}{$\begin{array}{l}\text { Proportion of marks } \\
\text { assigned to }\end{array}$} & \multicolumn{5}{|c|}{ Rank, $0^{\circ}$ to $100^{\circ}}$. \\
\hline Relative. & Absolute. & $55^{\circ}$ & $75^{\circ}$ & $95^{\circ}$ & $99^{\circ}$ & $99^{\circ} 99^{\circ}$. \\
\hline $\begin{array}{c}\text { All. } \\
\frac{1}{2} \\
\frac{1}{3} \\
\frac{1}{3} \\
\frac{1}{4} \\
\text { None. }\end{array}$ & 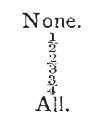 & $\begin{array}{l}1.0 \\
0.7 \\
0.6 \\
0.5 \\
0.4\end{array}$ & $\begin{array}{l}5^{\circ} \circ \\
3.5 \\
3^{\circ} \circ \\
2.7 \\
2^{\circ} \circ\end{array}$ & $\begin{array}{l}9.0 \\
6.9 \\
6.2 \\
5.8 \\
4.8\end{array}$ & $\begin{array}{l}9 \cdot 8 \\
8 \cdot 4 \\
8 \cdot 0 \\
7 \cdot 7 \\
7^{\circ} \cdot 2\end{array}$ & $\begin{array}{l}\text { I0. } \\
10^{\circ} \circ \\
10^{\circ} 0 \\
10^{\circ} \circ \\
10^{\circ} 0\end{array}$ \\
\hline
\end{tabular}

The general conclusion to which these remarks lead is, that before arranging scales of marks, the first step is to measure a large number of persons who are of the same class as the expected candidates; this has already been done to a considerable extent at Cambridge, at Marlborough College, and elsewhere. Thence to make tables, and to deduce diagrams from them like Fig. I in some cases, and like Figs. 2 and 3 in others. These will exactly determine the qualities of the men to be dealt with, in a statistical sense. It is now the part of those who have to fix the scales of marks to determine the grade at which rank shall begin to count, and to arrange the weight to be given respectively to relative rank and to absolute performance in each sort of examination. This and a few other obvious preliminaries having been settled, the construction of consistent scales of marks would follow almost as a matter of course.

Experiments at Eton College on the Degree of Concordance between different Examiners in assigning Marks for Physical Qualifications. By A. A. Somerville.

An experiment was made at Eton in July last, with the object of obtaining information upon the following points: (I) whether it is possible to frame a system of marking for physical excellence, based partly upon $\mathrm{Mr}$. Galton's system, and partly upon medical examination;

I The unit by which the deviations are measured is half the difference between the perfurmances of the persons who respectively occupy the grades $25^{\circ}$ and $75^{\circ}$.
(2) whether marks assigned by medical examiners would be as safe a test of excellence as those assigned, e.g. by examiners in English essay. The experiment was conducted as follows:-A list of points was drawn up with the help of two able medical men. These points were: (I) breathing capacity, as tested by the spirometer; (2) hearing - (3) eyesight, tested by Snellen's type ; (4) strength, tested by the grip dynanometer ; (5) endurance, tested as follows-after the maximum reading of the dynanometer had been obtained and registered for strength it was again (as nearly as possible) obtained, and the number of seconds during which the candidate could hold the needle of the dynanometer between this reading and the reading Io below it was taken by a stopwatch ; (6) relation of height to weight ; (7) girth and shape of chest; (8) general muscular development; (9) health record, particular inquiries being made as to rheumatism, asthma, and scarlatina: (IO) general aspect and condition.

The first five points depend solely upon measurement, and consequently the marks of the two doctors are the same for those points. The next point was marked, partly by impression and partly by reference to a table of averages, but it might be made to depend altogether upon averages. The seventh and eighth points were marked partly by measurement of chest, arms, and legs, and partly by examination. The last two points depend altogether upon medical opinion, and involved a thorough medical examination. Ten marks were assigned for each point, and the examination was conducted independently by the two doctors in separate rooms. Thirtytwo boys were examined: (I) twenty Army Class boys, including ten successful candidates at the recent Sandhurst and Woolwich Further Examinations, two members of the Cricket XI, and two members of the Rowing Eight; (2) six other members of the XI. ; (3) the remaining six members of the Eight. The following table gives the final results, average differences per cent. being calculated with reference to a maximum 50 , as the marks for the first five points are the same for the two examiners. (N.B.-Letters are substituted for the names of the boys.)

\begin{tabular}{|c|c|c|c|c|c|c|c|c|c|}
\hline \multicolumn{6}{|c|}{ Army B sys. } & \multicolumn{2}{|c|}{$\begin{array}{l}\text { Six Members of } \\
\text { the XI. }\end{array}$} & \multicolumn{2}{|c|}{$\begin{array}{l}\text { Six Members of } \\
\text { the Eight. }\end{array}$} \\
\hline $\begin{array}{l}\mathrm{A} \\
\mathrm{B} \\
\mathrm{C} \\
\mathrm{D} \\
\mathrm{E} \\
\mathrm{F} \\
\mathrm{G} \\
\mathrm{H} \\
\mathrm{I} \\
\mathrm{J} \\
\mathrm{Gre} \\
\mathrm{Le}\end{array}$ & $\begin{array}{l}5^{8 \frac{1}{2}} \\
74 \\
81 \frac{1}{2} \\
68 \\
72 \frac{1}{2} \\
44 \frac{3}{1} \\
65 \frac{1}{4} \\
66 \frac{1}{2} \\
69 \frac{1}{4} \\
7^{2} \\
\text { atest d } \\
\text { st diff }\end{array}$ & $\begin{array}{c}5^{8} \\
75^{\frac{1}{4}} \\
83 \\
69 \frac{1}{2} \\
70 \frac{1}{2} \\
46 \frac{1}{4} \\
68 \frac{1}{4} \\
63 \frac{1}{2} \\
72^{3} \\
76 \frac{1}{2} \\
\text { differe }\end{array}$ & $\begin{array}{l}\mathrm{K} \\
\mathrm{I} \\
\mathrm{M} \\
\mathrm{N} \\
\mathrm{O} \\
\mathrm{P} \\
\mathrm{Q} \\
\mathrm{R} \\
\mathrm{S} \\
\mathrm{T} \\
\mathrm{e} \\
\mathrm{P}\end{array}$ & $\begin{array}{l}53 \\
7 \mathrm{r}_{2}^{1} \\
57 \\
59 \frac{1}{2} \\
64 \\
5 \times \frac{1}{2} \\
57 \\
60 \frac{1}{2} \\
53 \frac{1}{4} \\
57 \\
.= \\
.= \\
.= \\
=\end{array}$ & $\begin{array}{c}56 \frac{1}{2} \\
77 \\
62 \\
65 \\
70^{\frac{1}{2}} \\
58 \\
65 \frac{1}{1} \\
70^{\frac{1}{2}} \\
62 \frac{1}{2} \\
70^{\frac{1}{2}} \\
13^{\frac{1}{2}} \\
\frac{1}{2} \\
\text { er cent. } \\
9.5\end{array}$ & $\begin{array}{l}\text { Great } \\
\text { fere } \\
\text { Least } \\
\text { ence }\end{array}$ & $\begin{array}{l}\text { st dif- } \\
\text { nce }=83 \\
\text { differ- } \\
. \cdot=1 \\
\text { Per cent. } \\
\text { ge dif } \\
\text { nce } .=9.5\end{array}$ & $\begin{array}{l}\text { Great } \\
\text { fer } \\
\text { Least } \\
\text { eno } \\
\\
\begin{array}{l}\text { Aver } \\
\text { fere }\end{array}\end{array}$ & $\begin{array}{l}\text { est dif- } \\
\text { nce. }=51 \\
\text { differ- } \\
\text { e. - }=x^{\frac{1}{2}} \\
\text { Per cent. } \\
\text { ge dif- } \\
\text { cee. } .=5.5\end{array}$ \\
\hline
\end{tabular}

Average difference for 32 boys ..... $\begin{aligned} & =4.375 \text { for max. } 50 \\ & =8.75 \text { per cent. }\end{aligned}$

Nineteen of the twenty Army boys were subsequently examined in English essay, the essays being marked independently by two examiners, with the following results :- -

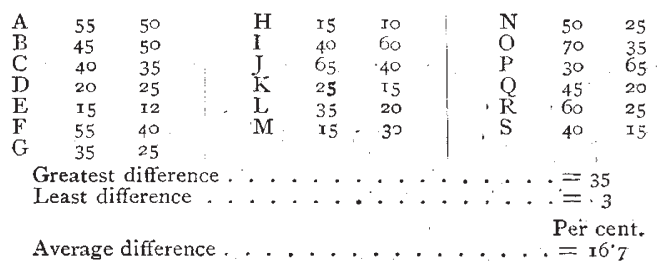


Comparing the average difference, 16.7 per cent., be tween the marks of the examiners in English essay, with the average difference, $9^{\circ} 5$ per cent., for the same boys, between the marks of the medical examiners, it seems fair to conclude that the marks assigned by the latter are at least as trustworthy as those given for English essay; which may be taken as a sample subject in a literary examination.

It is hoped that similar experiments will be undertaken at other places, so that materials may be obtained for the comparison and discussion of different systems of marking, and for the construction, ultimately, of the best systems. Such experiments would be rendered all the more valuable by the introduction of fresh points of examination, and by variations in the method of assigning the marks for the different points.

\section{NOTES.}

Ar a meeting of the Council of the Royal Society held on October 24, it was resolved that a Committee should be appointed to consider the desirability of raising some national memorial of the late Dr. Joule, and to take such action thereupon as they might think advisable. Sir Henry Roscoe was appointed the provisional Organizing Secretary.

THE W alker Engineering Laboratories in connection with University College, Liverpool, will be opened on November 2. The Lord President and Council of the College will entertain Sir Andrew Barclay Walker, Sir John Coode, the members of the Engineering Committee, and other distinguished guests at luncheon, served in the Walker Laboratories; and in the afternoon a public meeting will be held in St. George's Hall, at which Sir John Coode, President of the Institution of Civil Engineers, will deliver an address, and the annual distribution of medals and prizes will take place. In the evening there will be a reception at the Walker Laboratories, when the formal declaration of opening will be undertaken by the Hon. Lady Walker.

THE annual exhibition prepared by the South London Entomological and Natural History Society was opened at the Bridge House Hotel, London Bridge, S.E., yesterday, and will be open again this evening. These exhibilions have become so popular that on the last several occasions upwards of 2000 visitors have attended each evening.

Dr. S. Weir Mitchell, of Philadelphia, has been elected President of the Congress of American Physicians and Surgeons, which will meet in Washington in September 1891 .

As it is expected that the Forth Bridge will be opened for passenger traffic in the spring of 1890 , it is intended that the event shall be celebrated by the holding of an International Exhibition in Edinburgh, specially devoted to electrical and general inventions and industries. The Exhibition is under the patronage of the Queen; and the Marquis of Lothian, Secretary of State for Scotland, is the President. The Vice-Presidents include the Lord Provost of Edinburgh, the Lord Provost of Glasgow, the Lord Mayor (elect) of London, Mr. Edison, and Sir John Fowler. The executive have secured a site of about ninety acres in extent, within easy walking distance of the centre of the town. On Monday, at a special meeting of the Electrical Trades Section of the London Chamber of Commerce, a resolution was agreed to, appointing a Committee to consider the conditions on which it might be advisable to take part in this Exhibition.

A conversazione will be given by the Geologists' Association on December 6.

A statue of the French chemist, Nicolas Leblanc, is about to be unveiled at Saint-Denis. Leblanc was born at Issoudun in r753, and died in $\mathbf{1} 806$. He had a manufactory at SaintDenis.
THE following Science Lectures will be given at the Royal Victoria Hall during November:-November 5, Mr. A. P. Laurie, on "Dust"; November I2, Mr. W. Furneaux, on "The Heart, and how it beats"; November 19, Prof. Judd, "The Forge of the Blacksmith God"; November 26, Mr. J. E. Marr, "Grecnland's Icy Mountains."

THus Morley Memorial College for Working Men and Women, adjoining the Victoria Hall, has begun a very vigorous life. Over 450 students have joined within three weeks of the opening day. In fact they come in with somewhat embarrassing rapidity, and volunteers (both ladies and gentlemen) are urgently wanted, both to teach classes and act as librarians. Six librarians are wanted to take one evening a week each, from 8 to Io. The library has received a valuable present from Mr. Passinore Edwards, who has given Iooo books. Others have given smaller parcels, so that the book-cases which have been provided are quite inadequate, and more are needed.

Mr. William BURGess, the founder and proprietor of the Midland Counties Fish Culture Establishment, died on Sunday, at Malvern Wells.

LioyD's Agent at the Dardanelles telegraphed as follows on October 28, 9.45 a.m. :- "An earthquake was felt here on Saturday. Very little damage has been done. Sigri Light house, Mytilene, destroyed, also loss of life in island."

Prof. H. G. SEEley finds that the pubic bone, which is of large size, does not enter into the acetabulum in the Plesiosaurian genus Colymbosaurus from the Oxford Clay. In that genus, the clavicle and inter-clavicle are developed as small separate ossifications, on the visceral aspect of the large scapular arch, and hence are not usually seen.

AT the recent meeting of the Congress of German Men of Science and Physicians at Heidelberg, Iterr O. Ammon submitted to the Anthropological Section some interesting results of observations he had made in Baden. These observations related to 5000 soldiers. The tall men had generally long skulls, or skulls of medium length, whereas the short men had round skulls. Most of the round-skulled men came from the Black Forest; the long-sliulled usually belonged to the valley of the Rhine, and were especially numerous in towns and in the neighbourhood of the castles of ancient families. From this fact Herr Ammon concluded that the round-skulled men had been the original inhabitants of the Rhine valley, that they had been driven from it by long-skulled invaders, and that the latter had established themselves near the settlements of their victorious leatders. Having shown that there is a certain relation between the height of the figure and the shape of the skull, Herr Ammon went on to indicate the relation between fair hair and blue eyes. No fewer than 80 per cent. of the men with blue eyes had fair hair. He found also that physical growth is generally quicker in: the case of the brown-eyed than in that of the blue-eyed type.

AT the last meeting of the Andersonian Naturalists' Society of Glasgow, amongst the papers read was one by Mr. R. Turner Vice-President, on the Uredineæ and Ustilagineæ. He explained the relations of these microscopic Fungi to other plants, and their position in the vegetable kingdom. They are all parasitic upon some living plant, and consist of two essential elements -spores and mycelium. The spores are very diverse, the mycelium very similar. The same mycelium gives rise to several cifferent kinds of spores, each of these being formerly regarded is a different genus. The production of cluster-cups and of the spermagonia, with their so-called spermatia, was described. It was shown that these spermatia have been by no means established as equivalent to pollen in function. As an example of heterœcism, the life-history of Puccinea graminis was traced: first, the acidiospore stage on the barberry, then the rust on 